\title{
Feedback effects and social facilitation of vigilance performance: Mere coaction versus potential evaluation'
}

\section{ERIC KLINGER, ${ }^{2}$ University of Minnesota, Morris, Minn. 56267}

In an investigation of coaction effects on performance, $S \mathrm{~S}$ undertook a visual vigilance task in both isolation and coaction with a peer. Performance was improved by the presence of a coactor only when the coactor had access to information about the quality of the S's performance.

Since Zajonc (1965) revived interest in social facilitation effects, research has suggested that performance is improved by the presence of others provided that the performance employs dominant responses (Cottrell, Rittle, \& Wack, 1967) and that the "others" are spectators (Cottrell, 1968; Cottrell, Wack, Sekerak, \& Rittle, 1968), or coactors (Zajonc, 1966). However, the evidence supporting coaction effects in humans is somewhat mixed, and the operative element that is responsible for the effects has been largely unspecified. In a recent series of experiments with military personnel, Bergum \& Lehr (1963, 1964) found vigilance performance (detection of the omission of lights in a series) facilitated when performance was monitored by superior officers-a kind of evaluative audience-but no facilitative effects when peers worked in pairs. The latter experiment employed a rather easy detection task, however, and pairs of Ss were permitted to converse about any topic other than their single stimulus display, thus introducing an unknown amount of distraction.

The present experiment was designed to control communication and information exchange, and to compare the effectiveness of "mere coaction" (MC), in which Ss are engaged together in identical tasks while in visual contact but without other communication, and potential evaluation (PE), in which Ss not only coact but also have access to information concerning each other's errors.

\section{SUBJECTS}

Subjects were 48 paid, male undergraduates solicited randomly from a college directory.

\section{DESIGN AND OVERVIEW}

The vigilance task was adapted from a procedure described by Antrobus \& Singer (1964). Ss were asked to watch a flashing light and to press a switch each time a flash seemed brighter than the series of flashes in which it was embedded. Each $S$ performed in two sessions one week apart, once alone (A) and once paired (P) with another S. Ss were randomly assigned to the order of session in which they performed alone or paired (AP vs PA) and to the MC or PE conditions.

Under MC, Ss had no way of observing or evaluating their own or each other's performances. Under PE, the experimental room contained two buzzers, one in each rear corner behind the Ss. Whenever $\mathbf{S}$ missed a signal he was so informed by the buzzer nearest him. The procedure enabled $S$ to be informed not only of his own errors, but, in paired sessions, potentially also of his partner's. However, Ss were never instructed to attend to each other's performances, or instructed to compete with each other for accuracy.

The design thus created four main groups AP-MC, AP-PE, PA-MC, and PA-PE.

\section{APPARATUS}

Subjects sat in an IAC-402A audiometric room containing two signal displays, two chairs, and a small table between the chairs on which was mounted a screen to prevent each paired $S$ from seeing the other S's light, but permitting him to see the other S. A switch protruded from both sides of the screen to enable each $S$ to report when he thought he had seen a brighter-than-usual flash. The flashes appeared in a 1-in. round window of diffusive Plexiglas set in an 8-in. box. The windows were approximately $38 \mathrm{in}$. from the $\mathrm{S}$ 's eyes, subtending a visual angle of $1.5 \mathrm{deg}$.

The carrier stimulus lights maintained a uniform rate of $1 \mathrm{sec}$ on and $2 \mathrm{sec}$ off. Illuminometer readings indicated that the foot-candles of illumination were 90 for the signal light, 53 for the nonsignal light, 0.76 for the unlit window, 1.84 for the front side of the box around the windows, and 1.26 for the wall behind the box. Pilot Ss detected an average of $72 \%$ of the discriminative stimuli in the vigilance periods and $73.8 \%$ of the discriminative stimuli in the alert periods. Results reported in the following section show that our subsequent Ss detected $79 \%$ of the signals during alert periods. Ambient light in the room was provided by a single $60-\mathrm{W}$ frosted bulb placed behind, between, above, and equidistant from the Ss. A cumulative recorder marked thy $S$ 's responses, and the charts were marked manually by the $\mathrm{E}$ to indicate when discriminative stimuli were actually presented.

\section{PROCEDURE}

Subjects were telephoned and told that the experiment would involve two sessions of about $1 \frac{1}{4} \mathrm{~h}$ each. Ss who agreed to participate were instructed to enter the audiometric room at a scheduled time and take the chair with their name above it. All instructions were tape-recorded. Ss were instructed not to converse. Each session was preceded by a 1-min practico session that presented three discriminative stimuli to insure comprehension of instructions. Each session proper lasted for $56 \mathrm{~min}$, including two 3-min "alerts" at each end of the session to help form and maintain the necessary discrimination, and an intervening vigilance period of $50 \mathrm{~min}$. In the alert periods, three flashes out of 20 , or a total of nine per 3-min period, were discriminative signals, and in the vigilance period one flash out of 48 , or a total of 20 in $50 \mathrm{~min}$, was a discriminative signal. The 20 vigilance signals were apportioned so that six signals occurred in each of the first three periods of $15 \mathrm{~min}$ and two signals in the last 5 min. Signals were never scheduled for consecutive flashes. Within these restrictions, the schedule of signals was random. When Ss were paired, the carrier lights were turned on and off on identical schedules, but the brighter signal flashes were programmed independently for each $\mathrm{S}$.

The major dependent variable employed in analysis was the number of signals missed during vigilance periods. These false negative errors were identified as errors to $\mathrm{Ss}$ in PE conditions by their serving as the contingency for the error buzzer. False positive errors were recorded, however, and employed to help assess the nature of shifts in false negative error rates.

\section{RESULTS AND DISCUSSION}

Analyses of variance of false-negative errors revealed highly significant main effects of sessions and of $\mathrm{PE}(\mathrm{p}<.01)$, suggesting that performance was improved by practice-unexpectedly, in view of the initial training opportunities in the practice and alert periods-and by the feedback supplied to Ss by their buzzer concerning their own errors.

In analyzing the effects of coaction, the $\mathrm{MC}$ and $\mathrm{PE}$ conditions were first considered separately, the results in each constituting a crossover design which was analyzed in accordance with a procedure described by Chassan (1964). Since the means were correlated with their respective variances, the data were transformed by a variant of the 
Table 1

False-Negative Errors as a Function of Coaction, Potential Evaluation, and Session

\begin{tabular}{lllll}
\hline & AP-MC & $\begin{array}{c}\text { Group* } \\
\text { PA-MC }\end{array}$ & AP-PE & PA-PE \\
\hline Session 1 & & & & \\
M & 5.17 & 5.92 & 3.00 & 2.25 \\
SD & 3.21 & 5.35 & 1.65 & 2.30 \\
Session 2 & & & & \\
M & 2.75 & 3.75 & 0.58 & 2.00 \\
SD & 4.16 & 3.47 & 0.79 & 2.13 \\
\hline
\end{tabular}

* $N=12$ in each group

square-root transformation $[(\sqrt{x}+\sqrt{x+1})$ Winer, 1961, p. 220] in parametric analyses, and, as a further safeguard, the data were in some cases subjected to parallel nonparametric analyses.

Under PE (Table 1), Ss produced significantly fewer false-negative errors under coaction than under isolation $(t=3.01, p<.01, p=.008$ by a Fisher-Yates exact test of the direction of differences). Under MC, the presence of coaction left error rates unaffected $(t=0.06)$. The strength of association between coaction and error rate was .53 under PE and .01 under MC, by point-biserial correlation. The difference between the two coefficients yields $z=1.863, p<.10$ two-tailed. The effects of coaction under PE were homogeneous for the three thirds of each vigilance session (Fig. 1), the curves for the AP and PA groups crossing only with the change in the isolation-coaction variable between sessions.

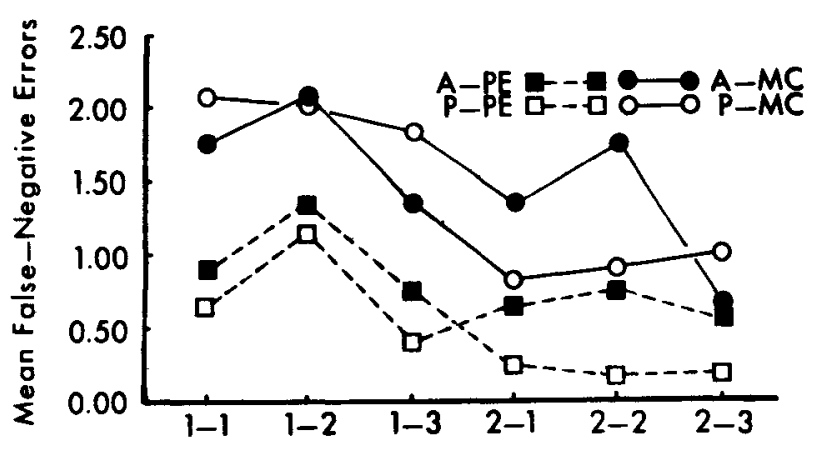

One-Third Session Blocks of Two Vigilance Periods

Fig. 1. False-negative errors as a function of coaction, potential evaluation, and sescion.
The main performance error variable considered here is the number of signals missed. Ss can decrease the number of their false-negative errors, i.e., failing to detect a signal when it was there, by increasing the number of their false-positive errors, that is, by adopting a less stringent criterion for reporting a signal, thus increasing the number of signal reports when the flash was not a signal. If this indeed occurred, improvement in the rate of correct detections would be related to an increase in false detections. An analysis of false-positive errors indicates that PE Ss' improved detection rate under coaction is not attributable to indiscriminate increases in call rates. The correlation between false-negative and false-positive error rates is slightly positive, .39 , which approaches significance at the .05 level.

Mere coaction, i.e., simply the presence of a coactor, was in this study insufficient to improve performance. Performance was improved, however, when the coactor had access to information about the $S$ 's performance, suggesting that potential evaluation is a necessary condition for coaction effects on performance.

\section{REFERENCES}

ANTROBUS, J. S., \& SINGER, J. L. Visual signal detection as a function of sequential variability of simultaneous speech. Joumal of Experimental Psychology, 1964, 68, 603-610.

BERGUM, B. O., \& LEHR, D. J. Vigilance performance as a function of paired monitoring. Journal of Applied Psychology, 1962, 46, 341-343.

BERGUM, B. O., \& LEHR, D. J. Effects of authoritarianism on vigilance performance. Journal of Applied Psychology, 1963, 47, 75-77.

CHASSAN, J. B. On the analysis of simple crossovers with uneaual numbers of replications. Biometrics, 1964, 20, 206-208.

COTTRELL, N. B. Performance in the presence of other human beings: mere presence, audience, and affiliation effects. In E. C. Simmel, R. A. Hoppe, \& G. A. Milton (Eds.), Social faciliation and imitative behavior. Boston: Allyn \& Bacon, 1968. Pp. 91-110.

COTTRELl, N. B., RITTLE, R. H., \& WACK, D. L. Pfesence of an audience and list type (competitional or noncompetitional) as joint determinants of performance in paired-associates learning. Journal of Personality, 1967, 35, 425-434.

COTTRELL, N. B., WACK, D. L., SEKERAK, G. J., \& RITTLE, R. H. The social facilitation of dominant responses by the presence of an audience and the mere presence of others. Journal of Personality \& Social Psychology, in press.

WINER, B. J. Statistical principles in experimental design. New York: McGraw-Hill, 1962.

ZAJONC, R. B. Social facilitation. Science, 1965, 149, 269-274.

ZAJONC, R. B. Social psychology: An experimental approach. Belmont, Calif.: Wadsworth, 1966.

NOTES

1. This research was supported by National Science Foundation Grant GS-1346.

2. The author thanks C. W. Gray for his generous consultative assistance, and R. $O$. Hietala for pervasive assistance with all aspects of the research.

\section{REFERENCES}

BUGELSKI, B. R. Presentation time, total time, and mediation. Journal of Experimental Psychology, 1962, 63, 409-412.

CHRISTIANSEN, T., \& STONE, D. R. Visual imagery and level of mediator abstractness in induced mediation paradigms. Perceptual \& Motor Skills, 1968, 26, 775-779.

GLAZE, J. A. The association value of nonsense syllables. Joumal of Genetic Psychology, 1928, 35, 259-269.

LINDQUIST, E. F. Design and analysis of experiments in psychology and education. Boston: Houghton-Mifflin, 1953.

MILleR, G. A., GAlanTER, E., \& PRIBRAM, K. H. Plans and the structure of behavior. New York: Holt, 1960.

PAIVIO, A. Learning of adjective-noun paired associates as a function of adjective-noun word order and noun abstractness. Canadian Journal of Psy chology, 1963, 17, 370-379.
NOTE

1. Christiansen, T., manuscript submitted for publication. 